\title{
Thermographic Analysis in Electronic Cycle Converters with Low Conductivity Loads
}

\author{
Javier Vargas ${ }^{1}$, Alexander Cucaita ${ }^{1}$, Fernando Riveros ${ }^{1}$ \\ Researchers EYSI Group, MACRYPT Group of the University of Llanos, Faculty of Basic Sciences e Engineering,
}

\begin{abstract}
The paper presents the results of an investigation was the general purpose of characterization and thermo-graphic evaluation electronic power semiconductor devices used in cyclo converters subjected to electric charges. To answer the question What is the thermal behavior of power electronic devices used for implementing a cycloconverter AC - DC and $\mathrm{AC}-\mathrm{AC}$, the framework of the cyclo converters AC - DC and $\mathrm{AC}$ - AC require power electronic devices such as diodes, transistors, and thyristors. These devices allow controlling current electrical power. Therefore it is necessary to characterize and evaluate the thermal performance of devices designed to show their behavior and thus determine the need for cooling systems to improve the energy efficiency of the system. The temperature of the power electronic devices, uncontrolled causes the device to become saturated causing damage to the intrinsic performance. Therefore by thermography technique, it is possible to characterize the behavior of the device and thus selecting a suitable option for heat dissipation. The methodology was divided into five phases and concluded that analyzes resulting from the application of the thermography technique indicated that the thermal behavior of the device is linear and not dependent on the type of load.
\end{abstract}

Keywords: Thermography, cycloconverters, BJT, SCR, TRIAC, power electronics, power electronic devices, transistors, thyristors.

\section{INTRODUCTION}

The purpose of the research focuses on the characterization and evaluation of the thermal behavior of the power electronic devices implemented in systems cyclo-converter AC-DC, ACAC electronic subjected to electric power loads. The proposed research is the experimental and quantitative approach, which is developed through consultation in scientific databases on technologies for thermo-graphic evaluation of power electronic devices used in implementing cyclo converters AC-DC, ACAC, defining design requirements electrical, electronic, and mechanical systems for cycle-conversion $\mathrm{AC}$ DC, AC-AC, the electronic systems implements cycleconversion, based on the design requirement,

Stop above a systematic mapping of literature was conducted, obtaining a scientific reference framework, which is presented below. The design of the converters cycles based on a control part and power, this is already required that the control part is formed by a circuit generating square waves, sinusoidal and/or triangular constant as a result of the power source DC, which can vary its frequency depending on the use to which they will be implemented; these circuits are considered to oscillator circuits that can be low, medium and high-frequency signals are to be repetitive.

Using oscillators converters is a high priority cycle, these being the heart of the circuit and are not as complex as are easy to use, achieving greater efficiency, and making the best of these. The power part consists of electronic components and highfrequency solid-state power which meets a unique feature that is to be mutated.

Following is a summary of articles, projects, and theses that are related to power circuits, electronic components operating at high voltage and frequency different uses and implementations of the same order solutions a problem of life or innovation will take place.

In the cases of the three-phase inverters for motors in $\mathrm{AC}$, processes specific modeling of three-phase motors, which use modulation processes based on carriers, in this case, PWM, to generate a signal that varies its frequency to control the phase inverter, poses a modulation scheme based and vectors capable of implementing hybrid modulation. [1]

The article "Study of efficiency MOSFETs and IGBTs for use in power converters commutated" performs general descriptions of the power transistors, tied into account the physical, material, and electrical characteristics. Perform the comparison of the IGBT and the MOSFET, which take into account the capacity and the density and current can circulate through them, the ability of dicipación heat between them since these devices operate at high retention and produce an increased temperature that could damage them and finally the applicability of fast switching high-frequency electrical circuits to power. These analyzes are supported by the information provided by the component manufacturers.[2]

"The problem to model and simulate the phenomenon of thermal conduction in three dimensions by moving the heat source towards the edges of the cell transistor, it is possible thus to assess the predictability of studies with approximate geometries. It is of particular interest to determine whether there are layers of material to achieve the critical temperatures before the previously estimated, which would lead to resize the trip times mitigation systems ".

The above is a part of the summary of the article called modeling three-dimensional burned by unique event, which focuses on the ability of heat dissipation of the power transistors, where modeling of the system is performed to analyze the influence of the heat radiated the transistor being close to other electronic 
components that make up the system, to assess whether there are previous failures and show that these elements disrupt the proper functioning of other devices, which leads to the transfer of part of the power to a facing away from the control circuits.[3]

Currently, the technology advances by leaps and bounds, improving the quality of electronic components, mainly efficiency and miniaturization, to make smaller and lighter devices; but due to the small size of the power components are have no capacity to dissipate all the power without producing excessive heat, and to facilitate removal of this power is the use of heat sinks.[4]

This paper presents a new control scheme of a wind generation system (SGE) connected to three-phase mains. The proposed control incorporates a follower of the maximum power point (MPPT) for optimal utilization of the wind resource. Also, the SGE adds compensation reactive power at the point of coupling to the mains, operating simultaneously and independently with the active power generation. The turbine used consists of a variable speed wind turbine fixed pitch, while the MPPT is implemented through a converter DC-DC voltage booster. A VSI three levels are used to interface with the three-phase AC mains[5]

There are different conversion techniques AD / DC singlephase systems to eliminate harmonics, these harmonics are produced due to the linearity of the components that are performing the conversion and this makes the power factor decreases. This can produce heating power transformers are generating losses, equipment failures, and increased energy costs; eliminating current harmonics is necessary to install a coil at the input of the system is trying to limit the input current and expand their driving time.[6]

Conventional and unconventional sources of energy sources are called hybrid systems, unconventional systems are characterized by the use of storage devices of energy, is the case of solar energy, waterfall among others, giving the advantage of energy not used immediately to take advantage of when required.

The systems power grid that is connected to a hybrid system requires a DC / AC converter robust capable of handling $100 \%$ energy demand and the need to be operable bidirectionally with the possibility of interconnection with other systems or networks. [7]

This article provides a brief description of existing renewable energy and its potential as energy resources is presented. This comprehensive package, choose solar PV.

Without delving, some regulations that must be met at the state level and expectations set mentioned there. Of these laws and offered aid to the sector largely depends on the future evolution of technology.

Photovoltaic panels are the main elements of these facilities, so its operation is described. These panels are grouped into sets to form the PV generator or "array" and require one or power that adequately converts the energy generated for subsequent use. These stages are known by the name of processor power systems.[8]
The design phase inverters connected to the network from renewable energy sources, the inverter must operate as a current source in phase with the mains voltage, injecting power to the distribution network, therefore, takes place the phase control from the switch with a PWM signal input transistor inverter that converts DC pulses into an AC signal in phase with the local line. [9]

Martin Delgado, Raul in his final work called "Design and experimental implementation of a single-phase inverter operating in island mode" gives us knowledge in designing and implementing experimental phase inverters being fully functioning models using unipolar and bipolar. [10]

The multilevel inverters are based on Cascading micro intermediate stage inverters with lifting and voltage reduction. The implementation of solar panels as a method of obtaining renewable energy in order unconventional different use methods of energy is high-impact care of the environment, but these systems are not as simple as they have investors voltage DC AC where generation circuits often implemented where with leads to the use of power transistors, in this paper make contributions to the conversion of current implementing models cascade, allowing greater control voltage which optimizes the factor power; the results of the study performance of this architecture will be achieved analytically,[eleven]

Currently, investors' voltage are designed with cutting-edge components, which spawn more power and applicability, these are implemented to replace the constant power consumption and help protect these same and the environment. The main objective of designing an investor in this article "INVESTORS DC voltage AC" is to save money, disconnecting from the home network and use the batteries which are charged with some kind of model collection of renewable energy.[12]

In power electronics must take into account the power amplifiers, which are converters that convert energy source polarization signal output, these may be of type $A, A B, B$, and $\mathrm{C}$, which have different identification for meters, raising the most important variables to consider with efficiency, power load and power dissipated in the transistor, these configurations have different performance than the amounts associated with the variables.[13]

\section{Predistortion DIGITAL APPLIED TO THE POWER}

AMPLIFIER SYSTEM EER is research, done by the group of radio engineering University Polytechnic of Madrid where they use operational amplifiers power (RF in this case), which achieve high performance as switches without having to use linear amplifiers. These amplifiers require the use of techniques such as Envelope Elimination and Restoration (EER) for linearity. Demonstrating the linearity of a system using digital pre-distortion techniques.[14]

Over the past two decades has innovated and developed technologies in transmission systems DC. Technological developments in equipment and power electronics have enabled the flexibility and modularity of interconnects various systems in $\mathrm{AC}$ and $\mathrm{DC}$.

In this sense, technology transmission systems high voltage DC, based converters voltage source, appears as a technological 
option extensive development thanks to the ease and flexibility offered in controlling the flow of active power and reactive between systems of different characteristics. Therefore, for proper operation of the transmission system on high voltage DC, regulation of the voltage is required at the DC bus and the flow of reactive power between the rectifier substation and the alternating current network with which it interconnects.

Article Design and implementation of linear controllers for regulating the DC bus converters VSC HVDC methodologies are set for modeling, identification, and design of controllers for regulating the DC bus and the flow of reactive power in a converter to source operating voltage rectifier. Additionally, control techniques are addressed state feedback applied to the converter voltage source. Finally, practical results of the implementation of a prototype converter in conjunction with controllers designed are presented.[fifteen]

The article called "Design and Implementation of a DC-AC For Excitation with Pulses Rectangular a Piezo actuator PZT" carries out the design and implementation of a power circuit of DC-AC for a piezoelectric actuator zirconated titanium lead this circuit stage and has control which is responsible for modifying the amplitude of vibration and power which stimulates activation of a MOSFET controlling the amplitude and signal shape. [16]

The network utilization snubber is applied to the increased efficiency of the sources, the article entitled "Analysis of Network Topologies Snubber for Power Transistors in switching power supplies" talks about the topologies used in switching power supplies and calculations necessary for its design, giving great importance to the proper design of networks eliminating parasitic resonance and on current peaks and intention. These are supported by practical circuits which show a substantial improvement in the performance of switching devices, enabling increased efficiency of the source.[17]

It should be borne in mind that the use of power devices with conditions rooted temperatures often exceed conditions that can support these same from design and manufacturing; then some research of thermography is displayed on power circuits.

"Application of thermography for comparing efficiency LED power" article by the engineer Teth Azrael Cortes Aguilar Institute, talks about a big problem of everyday life that is the efficiency and service life of LED lamps the which it is significantly reduced relative to the temperature in the lightemitting diodes. The compare study heat stress conditions the relationship between temperature, power consumption and radiation intensity of a LED 10-watt power between DC and a frequency of $200 \mathrm{~Hz}$ pulse width current modulated.

This work was performed using a thermal imaging camera to measure temperature and verify heat dissipation. Where it was found that a pulse width signal is more efficient to reduce the effect on the temperature rise of the LED junction, thereby ensuring better efficiency and longer life.[18]

The advance of new techniques to protect power circuits led to the development of prototypes that have infrared cameras, capable of automatically disabling devices that are above the standard factory settings, to ensure the safety of the users.
This device ensures the safety and recognizes the excessive proximity of a part of the human body to a tool that generates mechanical risks for the operator by analyzing the thermal image of the area surrounding the tool and, in this situation, proceed to triggering actions leading to the reduction or cessation of risks by stopping the machine automatically. [19]

"Failure Analysis and Evaluation Energy Anomalies Drivers Electric Power thermographic" is a written thesis by saqui

MOYOLEMA CLAUDIO FERNANDO of Ecuador, which speaks of device failure by overheating of electrical power conductors, these are studied and analyzed with the technique of thermography. Using the analysis mode and failure effect, it determined the different variables and possible failure modes using thermography as a preventive measure. The writer made this thesis to demonstrate that there is a loss of energy as heat in the electrical conductors, although the driver is with the right kind of cable.[20]

\section{THERMOGRAPHIC CHARACTERIZATION OF POWER DEVICES CYCLOCONVERTERS AC-DC, AC-AC}

The cycloconverter analyzed using a BJT transistor TIP Reference 31 as a power device. Table 1 presents the electrical parameters of the transistor under consideration.

Table 1. Parameters of the TIP Transistor 31

\begin{tabular}{|c|c|c|c|c|}
\hline SYMBOL & PARAMETER & & VALUE & UNIT \\
\hline \multirow{4}{*}{$V_{c B o}$} & \multirow{4}{*}{ Collector-Base Voltage } & TIP31 & 40 & \multirow{4}{*}{ v } \\
\hline & & TIP31A & 60 & \\
\hline & & TIP31B & 80 & \\
\hline & & TIP31C & 100 & \\
\hline \multirow{4}{*}{$V_{C E O}$} & \multirow{4}{*}{ Collector-Emitter Voltage } & TIP31 & 40 & \multirow{4}{*}{ v } \\
\hline & & TIP31A & 60 & \\
\hline & & TIP31B & 80 & \\
\hline & & TIP31C & 100 & \\
\hline $\mathrm{V}_{\mathrm{EBO}}$ & \multicolumn{2}{|l|}{ Emitter-Base Voltage } & 5 & v \\
\hline Ic & \multicolumn{2}{|c|}{ Collector Current-Continuous } & 3 & A \\
\hline $\mathrm{ICM}$ & \multicolumn{2}{|l|}{ Collector Current-Pulse } & 5 & A \\
\hline$I_{B}$ & \multicolumn{2}{|l|}{ Base Current } & 1 & A \\
\hline \multirow{2}{*}{$P_{c}$} & \multicolumn{2}{|l|}{$\begin{array}{l}\text { Collector Power Dissipation } \\
T_{C}=25^{\circ} \mathrm{C}\end{array}$} & 40 & \multirow{2}{*}{ w } \\
\hline & \multicolumn{2}{|l|}{$\begin{array}{l}\text { Collector Power Dissipation } \\
T_{a}=25^{\circ} \mathrm{C}\end{array}$} & 2 & \\
\hline$T_{i}$ & \multicolumn{2}{|l|}{ Junction Temperature } & 150 & $c$ \\
\hline$T_{\text {stg }}$ & \multicolumn{2}{|c|}{ Storage Ttemperature Range } & $-65 \sim 150$ & $c$ \\
\hline
\end{tabular}


Also, it was identified that the thermal behavior of the transistor on the package is linear. In case the temperature in encapsulated Table 2 presents the thermal behavior of the device.

Table 2. Thermal Performance BJT

\begin{tabular}{cc}
\hline $\begin{array}{c}\text { Encapsulated temperature } \\
\text { Temperature }\left({ }^{\circ} \mathrm{C}\right)\end{array}$ & $\begin{array}{c}\text { Power dissipation } \\
(\mathrm{W})\end{array}$ \\
\hline 20 & 20 \\
40 & 18 \\
60 & 15 \\
80 & 11.5 \\
100 & 8 \\
120 & 5 \\
140 & 1.7 \\
\hline
\end{tabular}

Of zero degrees Celsius to 30 degrees Celsius power dissipation is stable at $20 \mathrm{~W}, 30$ to 150 degrees Celsius the correlation coefficient is negative and behavior obeys equation 1 .

$$
\mathrm{Dp}=-0,1605 \mathrm{~T}+24,22
$$

Figure 1, shows the thermal performance of the power transistors used in cycloconverter AC - DC, AC-AC, with 110 VAC input and output 180VAC regulated.

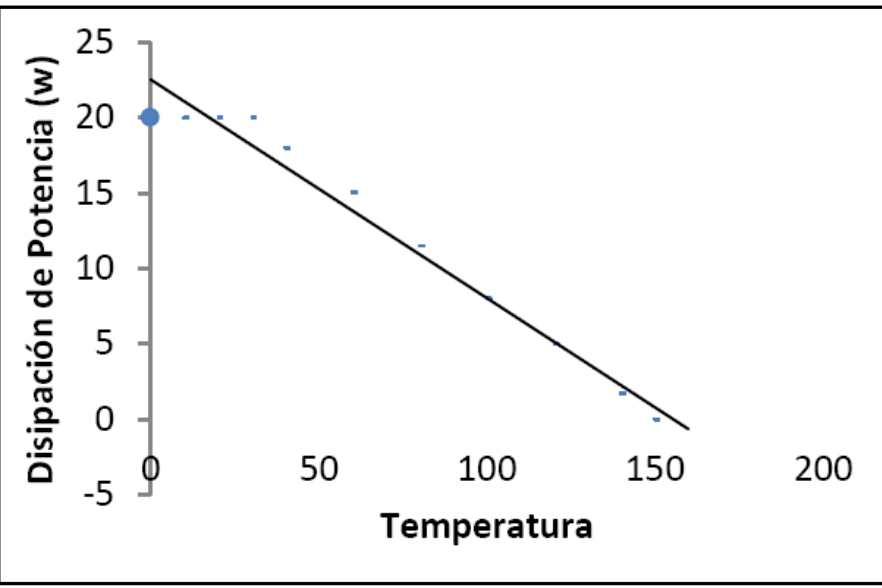

Figure 1. Thermal performance of the transistor TIP 31
Likewise, decision was made of thermal images of the cycloconverter graphic under study subjected to electric loads, Figure 2, shows the thermography performed on the device power BJT.
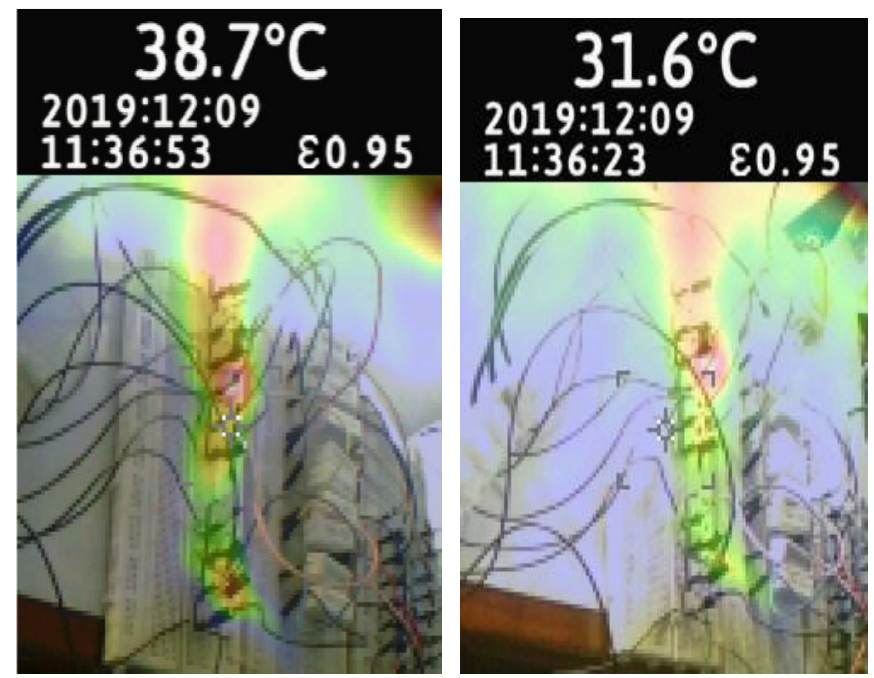

Figure 2. Images thermo graphic on power devices the cycloconverter under study.

Of zero degrees Celsius to 130 Celsius power dissipation it is linear with negative correlation coefficient and behavior obeys the equation number 2 .

$$
\mathrm{Dp}=-0,3941 \mathrm{~T}+51.46
$$
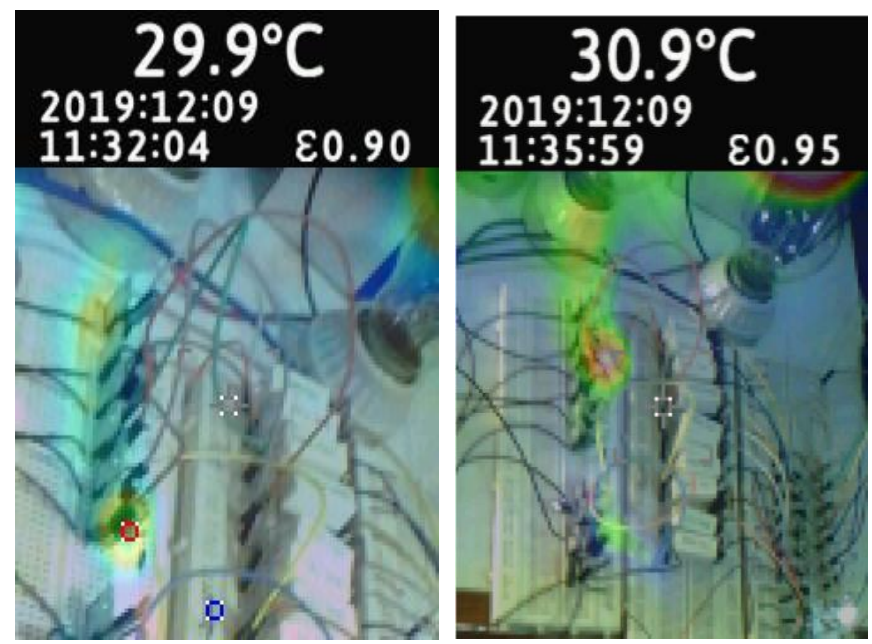

Figure 3. Thermal performance of the transistor SCR C106D

The cycloconverter analyzed using a reference SCR C106D as power device. Table 3 presents the electrical parameters of the transistor under consideration. 
The figure 3, presents the thermal behavior of the power transistors used in cycloconverter AC - DC, AC-AC, with 110 VAC input and output 180VAC regulated.
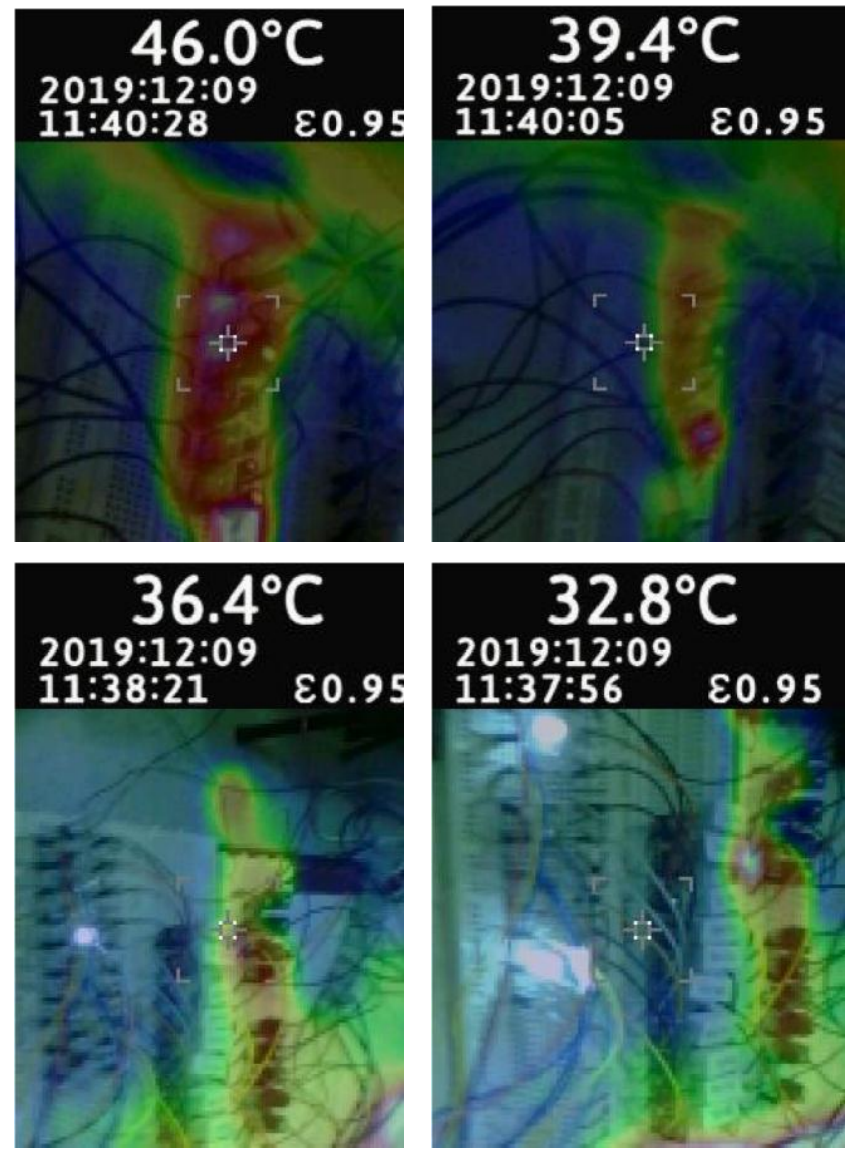

Figure 4. Images thermo graphic on power devices the cycloconverter under study.

Likewise, decision was made of thermal images of the cycloconverter graphic under study subjected to electric loads, Figure 4 presents thermography performed on the SCR power device.

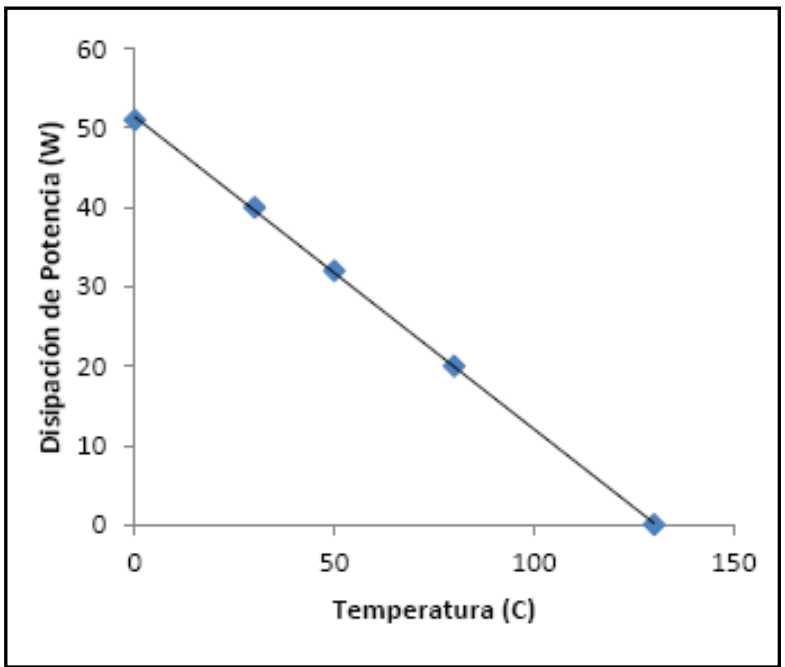

Figure 4. Thermography performed on the SCR power device
The cycloconverter analyzed using a TRIAC Reference BT136 as power device. Table 3 presents the electrical parameters of the transistor under consideration

Table 3. Thermal Performance SCR

\begin{tabular}{cc}
\hline $\begin{array}{c}\text { Encapsulation } \\
\text { temperature }\left({ }^{\circ} \mathrm{C}\right)\end{array}$ & $\begin{array}{c}\text { Power dissipation } \\
(\mathrm{W})\end{array}$ \\
\hline 0 & 70 \\
25 & fifty \\
fifty & 40 \\
75 & 25 \\
100 & fifteen \\
125 & 0 \\
\hline
\end{tabular}

Of zero degrees Celsius to 125 degrees Celsius power dissipation is linear with negative correlation coefficient and behavior obeys the equation number 3 .

$$
\mathrm{Dp}=-0,5371 \mathrm{~T}+66.905
$$

Figure 5 presents the thermal behavior of the power transistors used in cycloconverterAC - DC, AC-AC, with 110 VAC input and output $180 \mathrm{VAC}$ regulated.

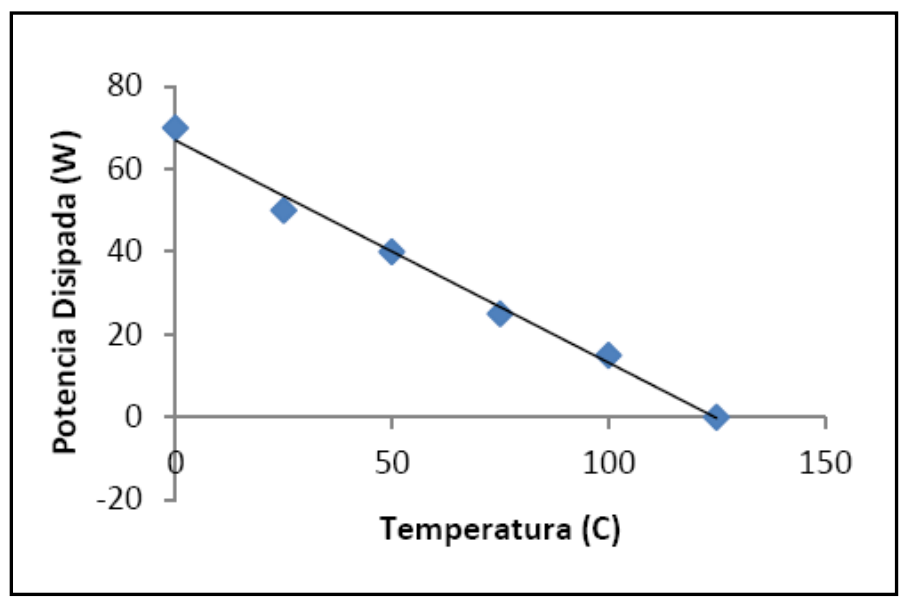

Figure 5. Thermal performance of the transistor TRIAC BT136

Likewise, decision was made of thermal images of the cycloconverter graphic under study subjected to electric charges, the figure 6 has thermography performed on the device power TRIAC. 


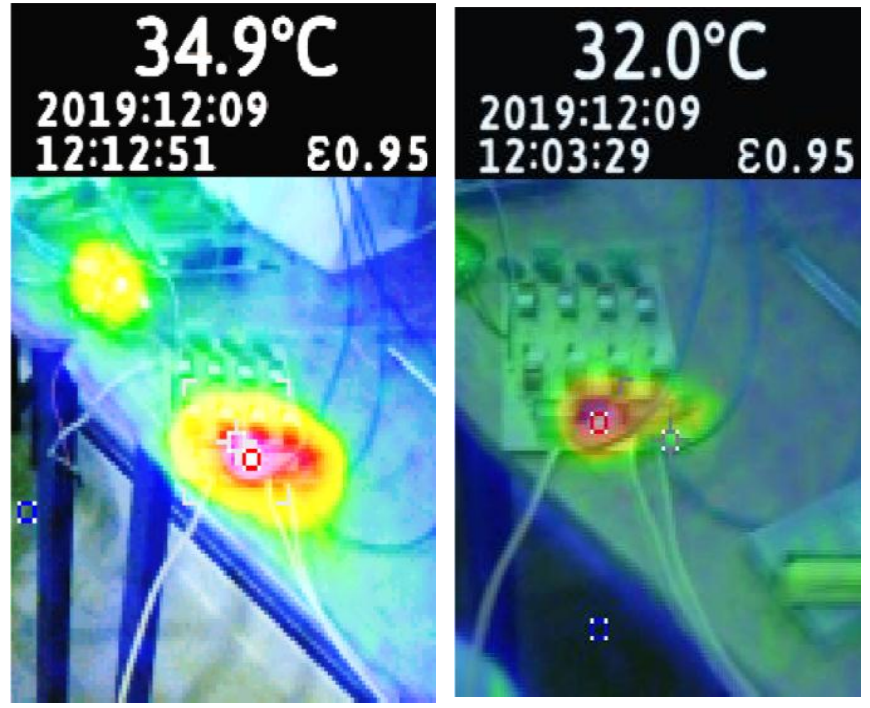

Figure 6. Images on graphic thermal power devices the cycloconverter under study.

\section{IMPACT OF ELECTRICAL LOADS IN TEMPERATURE OF SEMICONDUCTOR DEVICES SEMICONDUCTORS POWER}

Using thermography camera in the thermal behavior of the devices under resistive and inductive electrical loads allowed an observation of the temperature change to the loads. In Figure 7, the thermal behavior of the BJT Transistor device evidence in the variation of resistive and inductive loads.

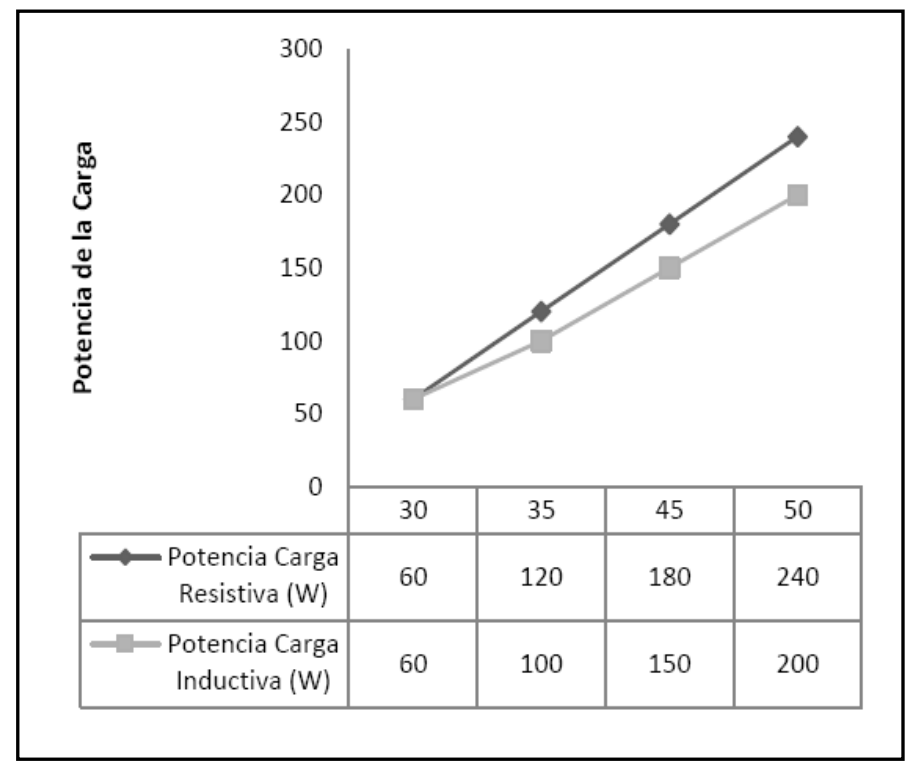

Figure 7. Thermal performance of BJT subjected to electrical inductive and resistive loads

Thus, the SCR device same linear behavior present in greater heat dissipation to the inductive load. The figure 8 shows the thermal response of the device to varying loads

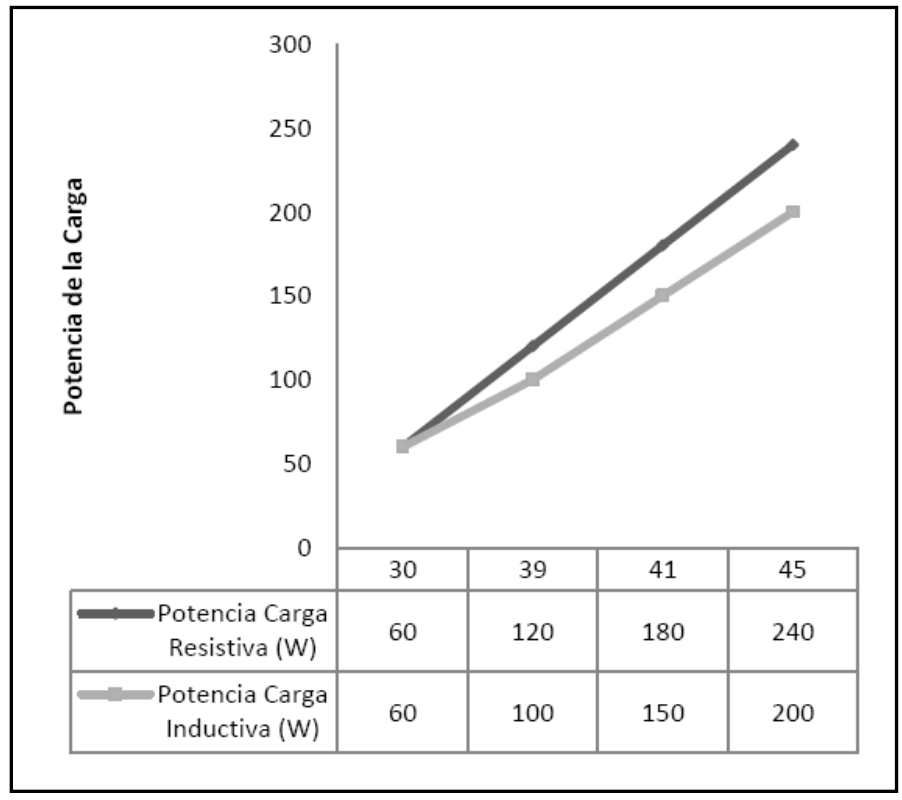

Figure 8. Thermal performance of SCR subjected to electrical inductive and resistive loads

Finally, the present device TRIAC linear behavior with greater heat dissipation to the inductive load. The figure 9 shows the thermal response of the device to varying loads.

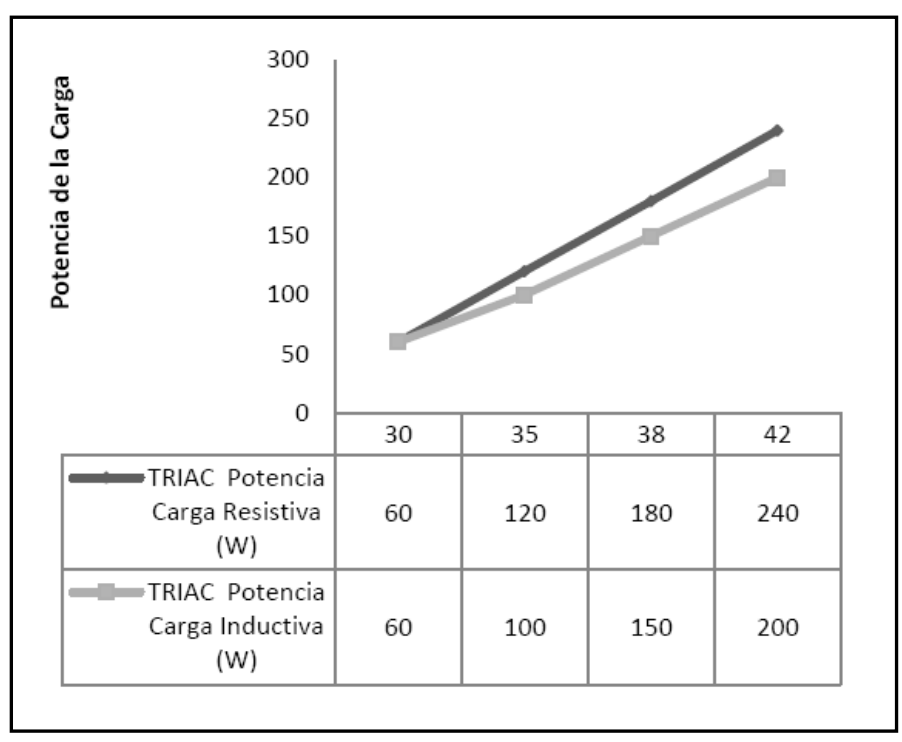

Figure 9. Thermal performance of electrical loads TRIAC subjected to inductive and resistive

\section{EVALUATION OF SINKS IN POWER DEVICES CYCLOCONVERTERS}

The thermal behavior of the devices implemented power in ciclconversor determined and underwent resistive electric charges and inductive, however the temperature was determined was about specific device on the package, in order to evaluate the thermal action of a heatsink on the power devices where an observation thermography could determine the influence of the heat sink on the device is performed. 
In the case of transistors, controlled rectifiers Sicilicio and TRIAC action sink was the same, the heatsink not help to reduce the temperature on nevertheless device allowed the temperature radiated onto the heatsink achieving uniformity encapsulating the device.

The figure 10 presents the thermal behavior of a transistor implemented heat sink aluminum material. It can be seen that the temperature is uniform in the sink, the red area is the hottest of the cycloconverter, for this case the temperature was $38.2^{\circ}$ C. Also, uniformity is observed in not finding points sink heat targeted or specific concentrations of encapsulating the transistor.

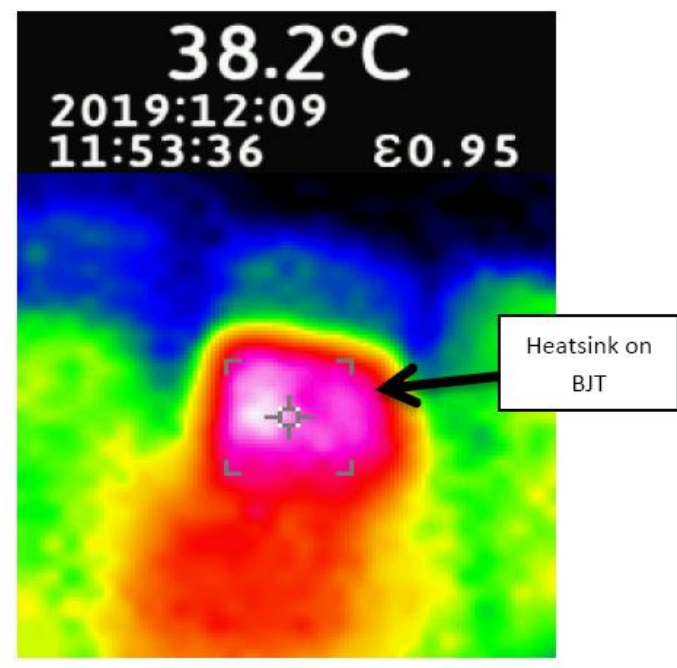

Figure 10. Thermal performance of sinks in BJT

In the case of the SCR, it is observed that the heat sink allows juna uniform distribution devices targeted and avoiding heat concentric zones which affect the efficiency of the devices even taking them to breakdown. Figure 11, we see that the temperature is $33^{\circ} \mathrm{C}$ and is uniform in the device.

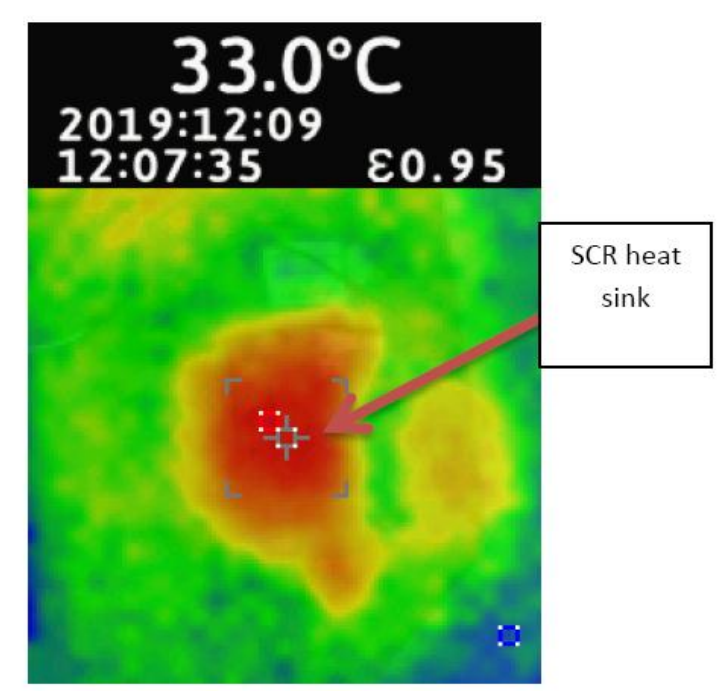

Figure 11. Thermal performance of sinks in BJT
In the case of the TRIAC, the cycloconverter is subjected to an inductive load of a three-phase motor squirrel cage $1 / 4$ horsepower, the sink in the two blocks of allowed devices concentrate the heat on two specific points and homogeneous making minimize hot spots focused on the area of encapsulation of the device. Figure 12, show a temperature of $51.4^{\circ} \mathrm{C}$ and a uniform distribution in the two sections of the TRIAC implemented on heatsinks.

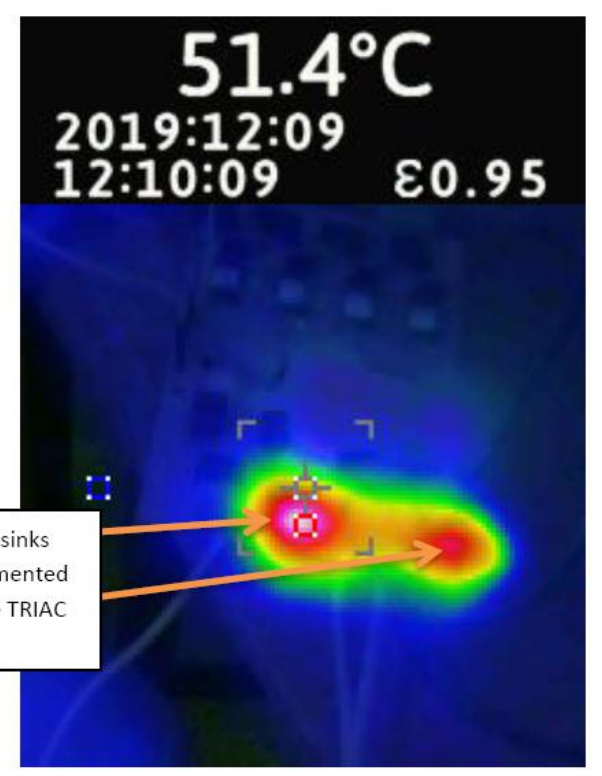

Figure 12. Thermal performance of sinks in TRIAC

\section{CONCLUSIONS}

The thermal behavior in power electronic devices BJT, SCR and TRIAC is negative linear correlation coefficient, thus increasing the temperature on the device increases the power dissipation.

The thermal nonlinearity is not dependent on the load connected to the cycloconverter and processes thermography allow qualitative real-time analysis of the behavior of the semiconductor device. The linearity is maintained even load is an inductive or nonlinear values are greater power dissipation in resistive loads which means that the force inductive loads at a higher temperature in a shorter time on the power device.

The action of the heat sinks on the power devices permit distribution of heat evenly on the plate preventing the targeting of hot spots on the encapsulation of the power device.

Thermography allows real time monitoring of temperature on the cycloconverter and on power devices under study, allows qualitative observation techniques for recording the thermal behavior of the device along the operating time or exposure loads .

\section{ACKNOWLEDGEMENTS}

The authors would like to thank the University of Los Llanos and the Directorate General of Research for funding and contributions to research in the area of power and industrial electronics. 


\section{REFERENCES}

[1] L. Mesa Et To The."Pwm Modulation Applied To ThreePhase Inverters Within The Scheme Of Ac Electrical Drives." Prim. Isa Show Andin. 2007 They Put., Pp. 1-24, 2007.

[2] Fhm Sarmiento, "Study Of Efficiency Mosfets And Igbts For Use In Power Converters Switched" Tecnura, Vol. 8, No. 15, Pp. 84-96, 2004.

[3] Ce Tais, Ea Romero, And Gl Demarco, "ThreeDimensional Modeling Burned By Unique Event In Power Transistors," Mechanical Comput., Vol. Xxx, No. October, Pp. 1-4 2011.

[4] F. Miyara, "Power Dissipation," Pp. 1-24, 2006.

[5] Mg Molina, Pe Market, And S. John, "Control Strategy To Maximize The Power Extracted From Variable Speed Wind Turbines Connected To The Grid," Av. Renov Energy. And Natural Environment., Vol. 12, Pp. 65-72, 2008.

[6] Fhm S, "Conversion Techniques Ac / Dc Single Phase Systems Unit Power Factor," Pp. 46-54, 2003.

[7] G. Moreno Et To The."Hybrid Electric Power Generation As An Alternative To Non-Interconnected Zones," 2007.

[8] J. Chavarria Roé Director And D. Biel Solé, "Design And Implementation Of A Multilevel Inverter For Grid Connected Pv Systems," 2009.

[9] C., U. Polytechnic, And Dv Valencia, "Design, Modeling And Implementation Of Inverter Connected To The Grid From Renewable Sources," Vol. 16, No. 32, Pp. 12-28, 2012.

[10] Martin R. Delgado, A. Lazaro Blanco, And V. Guerrero Valdivia, "Design And Experimental Implementation Of A Single-Phase Inverter Operating In Mode Island," Pp. 10166, 2012.

[11] A. Alvarez, "Contributions To The Dc-Ac Conversion In Photovoltaic Systems: M 'Odules Cascaded Inverters Connected To The Dc-Contribution Ac Converter In Photovoltaic Systems: Cascaded Microinverters," 2015.

[12] Esm Fontecha And Dillan Alejandro Torres Pérez, "Dc Ac Voltage Inverter Ed," 2012.

[13] Ji Huircan, "Power Ampli ... Ers," Pp. 1-19, 2012.

[14] M. Patino-Gomez, D. Tena-Branches, Fj OrtegaGonzalez, Manuel J., And P. Cesar, "Power For Digital Predistortion Eer System By," Pp. 2-5.

[15] Ca Hidalgo Mora, N1 Diaz Aldana, And Cl Trujillo Rodriguez, "Design And Implementation Of Linear Controllers For Vsc Hvdc Dc Bus Based Regulation," Tecnura, Vol. 18, No. 40, Pp. 48-61, 2013.

[16] A. Carmona, M. Arroyave, And Jm Jaramillo, "Design And Implementation Of A Dc-Ac Converter For Excitation Pulses Rectangular With A Piezo Actuator Pzt," Vol. 40, No. 12008.
[17] Ji Morales, "Analysis Of Snubber Network Topologies For Power Transistors In Switching Power Supplies," Pp. 1-6.

[18] Tac Jv Aguilar And Aguilar, "Application Of Thermography For Comparing Efficiency Led Power," No. January, Pp. 0-5, 2016.

[19] Jr Valverde, "New Safety Devices On Machines Using Thermal Imaging Cameras," 2013.

[20] Cf Saqui Moyolema, "Failure Analysis And Energy Assessment Of Anomalies In Electrical Power Conductors Using Thermography.," 2016. 